\title{
Benign Versus Malignant Solid Breast Masses: US Differentiation
}

\author{
Abdoelrahman Hassan A. B ${ }^{1}$, Osama Satti, MD ${ }^{2}$ \\ ${ }^{1}$ Sudan University of Science and Technology, COMRS, Khartoum, Sudan \\ Anatalya Diagnostic Medical Center, Khartoum, Sudan \\ ${ }^{2}$ Alfaisal Specialized Hospital, Khartoum, Sudan
}

\begin{abstract}
Retrospective study was aims to evaluate the significance of specific Ultrasonographic (US) imaging features to distinguish between benign and malignant solid breast masses, with biopsy (Cytologic or histologic) results as the reference standard and to determine whether solid breast masses that were diagnosed as probably benign only at ultrasonography (US) can be safely managed with follow-up. Materials \& methods: One hundred females with solid breast nodules presented to KTH breast clinic for breast evaluation from April 2011 to April 2012. Sonographic features were compared finally with biopsy (FNAC) results. The significant statistical values of the sonographic features were calculated. The main study result was; the age range of the patients was between 1575 years with a mean age of 29 years. Benign histologic features were found in $76 \%$ lesions; malignant histologic features, in $24 \%$. The US features most predictive of a benign tissue diagnosis were oval \& round shaped (72\%), well circumscribed margin (86.9\%) and with macrolobulations (100\%), with homogenous echo texture (94.4\%), with dimensions of wider than deeper (91.9\%), had posterior acoustic enhancement (90\%) and the presence of thin echogenic pseudocapsule around the mass (100\% of the masses with this feature were benign).The features most predictive of malignant tissue were speculated \& mcirolobulated (86.7\% and 66.7\% respectively), irregular shaped \& ill-defined angular margin (81.8\% and $78.6 \%)$, with dimensions of deeper than wider (71.4\%), with posterior acoustic shadowing (75\%), had ductal extension (100\%) and showed heterogeneous echo texture (82.1\%). Sonography can be used to accurately classify some solid lesions as benign, allowing imaging follow-up rather than biopsy.
\end{abstract}

Keywords: breast mass, ultrasonography, echo texture and FNAC.

\section{Introduction}

Remarkably, sonography of the breast has been performed both in vitro and clinically for 53 years which play a significant role in diagnosing of breast disease and masses also it was used for guiding needle biopsy. Breast biopsy, the current method used to distinguish between benign and malignant breast abnormalities seen at imaging [1] but readily the US used to differentiate between the solid and cystic masses in addition to benign and malignant lesion using different US echo-texture feature. Furthermore, the Agency for Healthcare Research and Quality recently asserted that current US examinations are neither sufficiently sensitive nor adequately specific to be used in place of breast biopsy for the diagnosis of mammographically identified abnormalities [3]. Anatomically about 15-20 lactiferous ducts open on to the nipple. The nipple itself is surrounded by the areola, which contains large sebaceous glands that are often visible to the naked eye - the glands of Montgomery [5].

For diagnostic benefits; the normal sonographic anatomy, including skin, subcutaneous fat, glandular tissue with interspersed Cooper's ligaments, retroglandular fat, pectoral muscles, ribs, and pleura [6]. The time-gain compensation curves are set to a uniform median level of echogenicity (gray) from the skin to the pectoral muscle. The skin appears as a uniform gray layer at the most superior aspect of the image between two bright white hyperechoic lines [6], that measures up to $3 \mathrm{~mm}$ in thickness. The hyperechoic lines represent the interface separating the skin from the transducer above and the underlying subcutaneous fat below. The subcutaneous tissue appears as a hypoechoic (darker) layer below the skin. Fat in the subcutaneous tissue and in the retromammary region and even areas of fatty involution within the breast parenchyma have a similar echogenicity. The glandular tissue below the subcutaneous fat has an echogenicity similar to the skin also we have to consider that the fatty tissue Ultrasonographic appearance varies from older and younger ladies [6].

Breast mass may be benign or malignant, the early detection of the breast masses depend on the screening programs which is According to the American Cancer Society, breast cancer screening involves (1) monthly breast self-examination (BSE), (2) regular clinical breast examination (CBE) by a physician or other health care provider, and (3) screening mammography [9]. In order to evaluate the patient with breast mass the following point should be considered; Patient age, Risk factors for breast cancer and Onset and duration of mass-Relation to menstrual cycle. Breast Examination (For a palpable mass) include: Location of mass (clock face or quadrant) which may have Characteristics of: Size, shape (round, oval, lobular, irregular), Surface contour (smooth, irregular) and Consistency (soft, rubbery, firm, hard, and gritty) also Mobility (movable, fixed) [9]. US, CT, MRI and FNAC in addition to the core biopsy are considered as slandered method to diagnose the breast mass. Palpable breast lump is a reason for breast US when the clinical patient information should be taken into account. Sonographic Characteristic of common Breast masses can include: Simple cyst which characterized by (Oval to round, Anechoic, Imperceptible capsule, Posterior acoustic enhancement, Edge refraction and Often compressible). Also Complex cyst (Intracystic mass, Irregular or thickened wall, Fluid levels, Debris, Particulate echoes and Shadowing).

\section{Volume 4 Issue 12, December 2015}




\section{International Journal of Science and Research (IJSR) \\ ISSN (Online): 2319-7064}

Index Copernicus Value (2013): 6.14 | Impact Factor (2014): 5.611

Fibroadenoma (Hypoechoic, Uniform echogenicity, Smooth, sharp border, Wider than tall, Posterior acoustic enhancement, and Edge refraction). But cancer may have (Irregular, speculated, or angulated border, Hypoechoic, Heterogeneous echogenicity, Taller than wide, Indistinct margins, Boundary echoes, and Posterior acoustic shadowing (usually)). From this points the researcher concluded that the sonographic BI-RADS lexicon was useful in differentiating between benign and malignant solid masses.

The BI-RADS lexicon requires the breast imaging report be summarized into 1 of 7 possible categories: BI-RADS 0 , further assessment required; BI-RADS 1, negative study; BIRADS 2, benign finding (risk of malignancy similar to that of the surrounding parenchyma); BI-RADS 3, probably benign finding (less than $2 \%$ risk of malignancies should be followed up at 6,12 , and 24 months, and then classified as benign category 2 after showing stability for 24 months or biopsied if concerning changes or growth are seen); BIRADS $\mathbf{4}$, lesion is suspicious for malignancy (biopsy is offered); $\boldsymbol{B I}$ $\boldsymbol{R A D S} 5$ lesions are highly suggestive of malignancy; and $\boldsymbol{B I}$ $\boldsymbol{R A D S} \boldsymbol{6}$ lesions are biopsy-proven malignant before surgery is obtained (it is suggested that appropriate actions should be taken for these categories)[11].

There are certain advantages for performing aspiration, biopsy, or localization with ultrasound guidance, where the accurate needle placement (Fornage et.al 1987) [15], fine needle aspiration biopsy can have a high sensitivity rate of $95 \%$ and NPV of 98\% [13], In 1993, Parker et al [16] reported the use of core needle biopsy of the breast using real-time ultrasound.

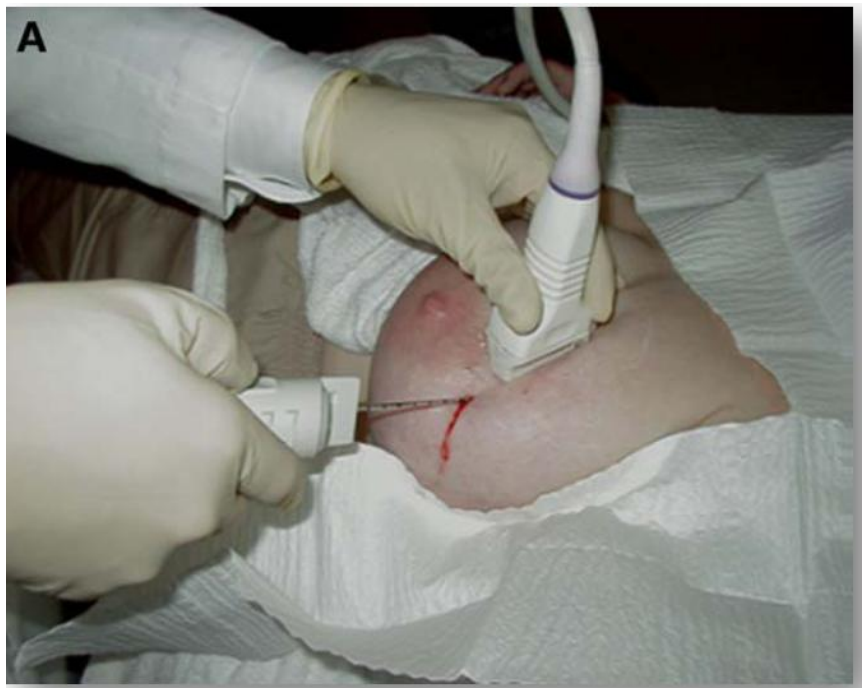

Figure 1: Showed the US guided needle biopsy for breast

Harlow et al [18] used intraoperative ultrasound to excise 65 breast cancers and reported achieving negative excision margins at first operation in $97 \%$.

\section{Material and method}

A cross-sectional (descriptive) hospital based retrospective study carried out to differentiate between the benign and malignant lesion of breast tumors in reference to the FNAC reports, 100 women who presented complain of breast abnormality to the KTH breast clinic for breast evaluation, and consecutively underwent full clinical examination, ultrasound \& biopsy where the US result confirmed by the biopsy result in a period from April 2011 to April 2012. A supine position used to exam the patient with US then all US examinations were performed with a $7 \mathrm{MHz}$ or above lineararray transducer. The scanning protocol included both transverse and longitudinal real-time imaging of the solid masses. Radiologists specializing in breast imaging performed the examinations. we reviewed the hard-copy US images \& radiologist's report of the solid masses, to assess the following criteria from the literature : shape (oval, round, lobulated, or irregular), margins (circumscribed, ill defined, spiculated, or microlobulated), width-to-anteroposterior (AP) dimension, posterior echoes (enhanced, unaffected, or decreased), echogenicity (intensity of internal echoes), echotexture (homogeneity of internal echoes), presence of calcifications, presence of ductal extension, and presence of a pseudocapsule. Each US characteristic was analyzed using IBM SPSS statistical package (21.0) to determine its association with a benign versus malignant tissue diagnosis. The final assessment categories were compared with the tissue diagnoses to determine sensitivity, specificity, and positive predictive value for US. A $\chi^{2}$ test was used to determine statistical significance.

\section{Result}

Table 1: The relation between the Shape \& FNAC biopsy result:

\begin{tabular}{|c|c|c|c|c|}
\hline & & Benign & Malignant & Total \\
\hline \multirow{3}{*}{ Oval } & Count & 61 & 1 & 62 \\
\cline { 2 - 5 } & $\%$ within Shape & $98.4 \%$ & $1.6 \%$ & $100.0 \%$ \\
\hline \multirow{2}{*}{ round } & Count & 11 & 5 & 16 \\
\cline { 2 - 5 } & $\%$ within Shape & $68.8 \%$ & $31.3 \%$ & $100.0 \%$ \\
\hline \multirow{3}{*}{ iregular } & Count & 4 & 18 & 22 \\
\cline { 2 - 5 } & $\%$ within Shape & $18.2 \%$ & $81.8 \%$ & $100.0 \%$ \\
\hline Total & Count & 76 & 24 & 100 \\
\cline { 2 - 5 } & $\%$ within Shape & $76.0 \%$ & $24.0 \%$ & $100.0 \%$ \\
\hline \multicolumn{5}{|c|}{ Correlation is significant at p $=0.000$} \\
\hline
\end{tabular}

Table 2: Showed the correlation lobulation and FNA biopsy result

\begin{tabular}{|c|c|c|c|c|}
\hline & & Benign & Malignant & Total \\
\hline \multirow{2}{*}{$\begin{array}{l}\text { small in size }(1 \\
2 \mathrm{~mm}) \&>3\end{array}$} & Count & 5 & 10 & 15 \\
\hline & $\begin{array}{l}\% \text { within } \\
\text { Lobulation }\end{array}$ & $33.3 \%$ & $66.7 \%$ & $100.0 \%$ \\
\hline \multirow{2}{*}{$\begin{array}{c}\text { large in size } \& \\
<3\end{array}$} & Count & 29 & 0 & 29 \\
\hline & $\begin{array}{l}\% \text { within } \\
\text { Lobulation }\end{array}$ & $100.0 \%$ & $.0 \%$ & $100.0 \%$ \\
\hline \multirow[t]{2}{*}{ No } & Count & 41 & 12 & 53 \\
\hline & $\begin{array}{l}\% \text { within } \\
\text { Lobulation }\end{array}$ & $77.4 \%$ & $22.6 \%$ & $100.0 \%$ \\
\hline \multirow[t]{2}{*}{ Total } & Count & 75 & 22 & 97 \\
\hline & $\begin{array}{l}\% \text { within } \\
\text { Lobulation }\end{array}$ & $77.3 \%$ & $22.7 \%$ & $100.0 \%$ \\
\hline
\end{tabular}

\section{Volume 4 Issue 12, December 2015}




\section{International Journal of Science and Research (IJSR) \\ ISSN (Online): 2319-7064}

Index Copernicus Value (2013): 6.14 $\mid$ Impact Factor (2014): 5.611

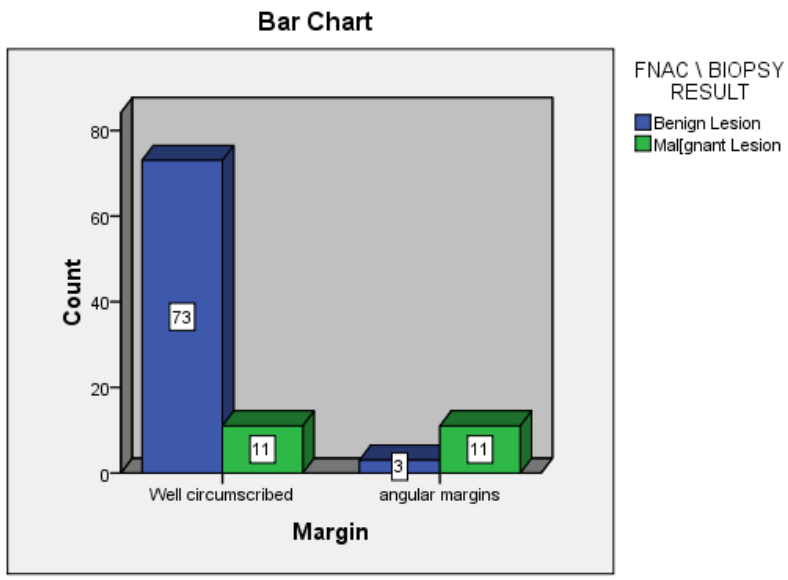

Figure 1: Showed the result pearson corraltion between the lesion marginal shape and the FNC biopsy result

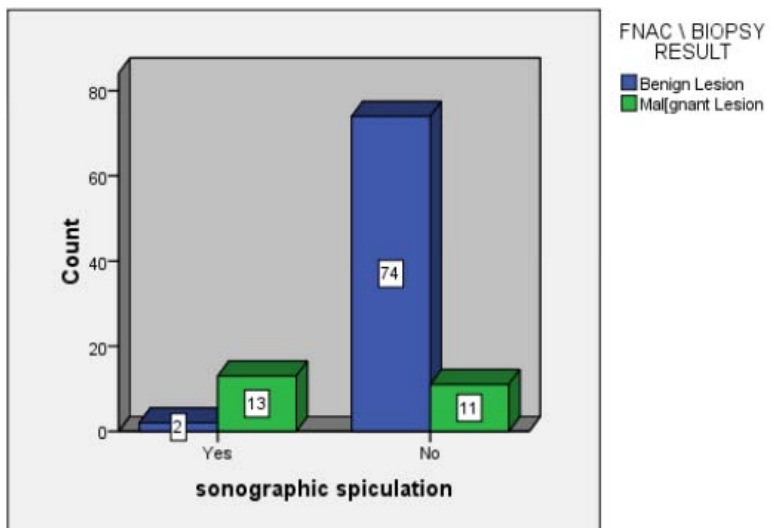

Figure 2: Demonstrate the relation between the preseance of sonographic spiculation and the FNA cytology result.

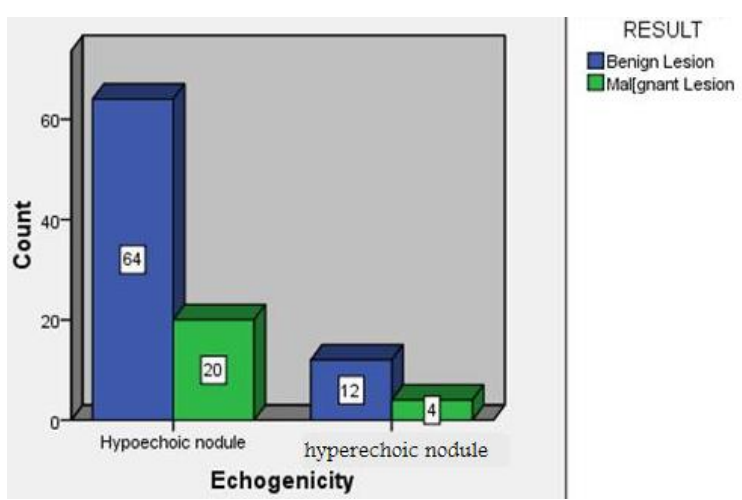

Figure 3: Showed the correaltion between the echogenicity and the Fine Needle Aspiration Cytology result.

Table 3: The relation between the Posterior Echo Intensity \& FNAC $\backslash$ biopsy result:

\begin{tabular}{|c|c|c|c|c|}
\hline & & $\mathrm{B}$ & $\mathrm{M}$ & Total \\
\hline \multirow{2}{*}{$\begin{array}{c}\text { sonographic } \\
\text { shadowing }\end{array}$} & Count & 5 & 15 & 20 \\
\cline { 2 - 5 } & $\begin{array}{c}\text { \% within Posterior Echo } \\
\text { Intensity }\end{array}$ & $25.0 \%$ & $75.0 \%$ & $100.0 \%$ \\
\hline $\begin{array}{c}\text { posterior } \\
\text { acoustic } \\
\text { enhancement }\end{array}$ & Count & 63 & 7 & 70 \\
\cline { 2 - 5 } & $\begin{array}{c}\text { \% within Posterior Echo } \\
\text { Intensity }\end{array}$ & $90.0 \%$ & $10.0 \%$ & $100.0 \%$ \\
\cline { 2 - 5 } & Count & 8 & 2 & 10 \\
\cline { 2 - 5 } & $\begin{array}{c}\text { \% within Posterior Echo } \\
\text { Intensity }\end{array}$ & $80.0 \%$ & $20.0 \%$ & $100.0 \%$ \\
\hline Total & Count & 76 & 24 & 100 \\
\hline \multicolumn{4}{|c|}{ Correlation is significant at p=0.000 } \\
\hline
\end{tabular}

Table 4: Demonstrate the correlation between the preseance of ductal extention and the fine needle biopsy result.

\begin{tabular}{|c|c|c|c|c|}
\hline \multicolumn{2}{|c|}{ ductal extension } & $\begin{array}{r}\text { Benign } \\
\text { Lesion }\end{array}$ & $\begin{array}{c}\text { Malignant } \\
\text { Lesion }\end{array}$ & Total \\
\hline \multirow{2}{*}{ Yes } & Count & 0 & 5 & 5 \\
\cline { 2 - 5 } & \% within ductal extension & $0.0 \%$ & $100.0 \%$ & $100.0 \%$ \\
\hline \multirow{2}{*}{ No } & Count & 76 & 19 & 95 \\
\cline { 2 - 5 } & \% within ductal extension & $80.0 \%$ & $20.0 \%$ & $100.0 \%$ \\
\hline \multirow{2}{*}{ Total } & Count & 76 & 24 & 100 \\
\cline { 2 - 5 } & \% within ductal extension & $76.0 \%$ & $24.0 \%$ & $100.0 \%$ \\
\hline \multicolumn{4}{|c|}{ Correlation is significant at p=0.000 } \\
\hline
\end{tabular}

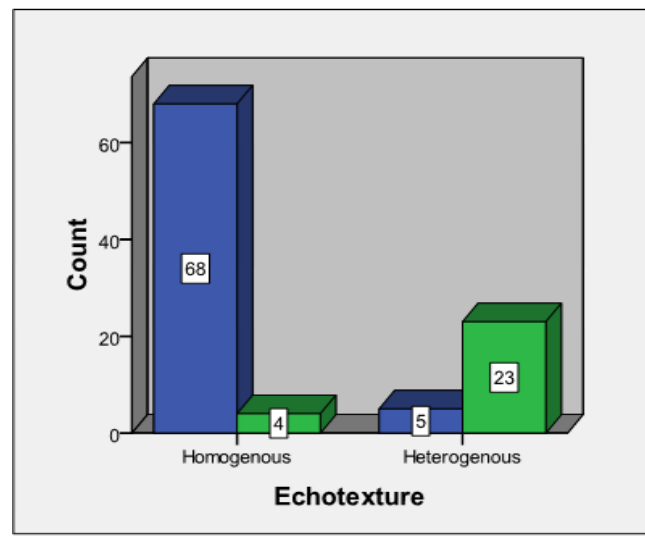

FNAC $\backslash$ BIOPSY RESULT

$\square$ Benign Lesion Malignant Lesion

Figure 4: Showed the correaltion between the echo-tecture and the Fine Needle Aspiration Cytology result.

\section{Discussion}

The age distribution of our study population was found to be, 43 patients between 14-25 years (43\%), 18 patients between 26-30 years (18\%), 17 patients between $31-40$ years $(17 \%)$ and 22 patients of more than 41 years $(22 \%) .22$ of them had previous history of breast disease and the majority of them were found to be due to previous lumpectomy (in 15 patients) and previous history of mastectomy (in 4 patients). All of our study population had no history of hystero-oophorectomy or ovarian cancer. The reasons for the recent breast examination in the majority of these cases were found to be due to detectable lump (in 92 patients). For an individual US characteristic to be deemed to have practical applicability in the differentiation of benign from malignant lesions, we concluded that it must: (a) be present frequently, (b) help reliably distinguish benign from malignant lesions.

Core-needle biopsy is now widely used for the evaluation of non-palpable solid masses and is readily adaptable to US guidance .Tissue diagnosis had been performed to all of our study population either core-needle biopsy (12 cases) or FNAC (88 cases), which result in diagnosing 76 benign masses ( 71 of them were Fibroadenoma) and 24 malignant masses ( 21 of them were invasive ductal carcinoma).

The reported considerable overlap of sonographic features in benign and malignant tumors reflects the common overlap in border characteristics and internal structure for benign and malignant tumors on gross pathology. Therefore this overlap is not entirely attributable to the imaging system but to a large degree to the tumors themselves. 


\section{International Journal of Science and Research (IJSR) \\ ISSN (Online): 2319-7064}

Index Copernicus Value (2013): 6.14 | Impact Factor (2014): 5.611

Shape can be an important predictor of malignancy if irregularity is present. It was found in $81.8 \%$ of malignant masses and $18.2 \%$ of benign masses. But a round and oval shape is a significant predictor of benignity. It was found in $68.8-98.4 \%$ of benign masses and in $1.6-31.3 \%$ of malignant masses (table .1) (correlation is significant at $\boldsymbol{p}=\mathbf{0 . 0 0 0}$ ). We grouped round and oval tumors as one category as some previous authors had done. Recent studies have shown that the ratio of the width $(\mathrm{w})$ of the tumor to its antero-posterior (AP) diameter (W: AP ratio) might be an important criterion in the characterization of breast masses .In our study, we found that $\mathrm{W}$ : AP ratio was an important predictive value in differentiating benign Vs malignant masses in our analysis. The dimension of wider than deeper is a predictor of benignity .It was found in $91.9 \%$ of the benign masses. But we found that the dimension of deeper than wider is a significant predictor of malignancy. It was found in $71.4 \%$ of the malignant masses (with $\mathrm{P}$ value less than 0.05 ). A few gently curving, circumscribed lobulation (macrolobulations) are considered a benign feature (100\% of the masses with this feature were benign), whereas many small lobulation of 1-2 $\mathrm{mm}$ (microlobulations) are considered a malignant characteristic $(66.7 \%$ were malignant) in our study analysis (table .2) (correlation is significant at $\mathbf{p}=\mathbf{0 . 0 0 0}$ ).

Margin is one of the most important sonographic tumor features (figure .1). A pseudocapsule is a strong predictor of a benign lesion $(100 \%$ of the cases with this features were benign) with statistically significant $\quad(P$ value $=0.03)$. The identification of the hyperechoic pseudocapsule can be impossible if the mass is surrounded by echogenic fibroglandular tissue.

Spiculated \& angular margin, a -malignant" finding, has been reported in $86.7 \%-78.6 \%$ of malignant masses respectively (figure .2). A well circumscribed contour, reported in $86.9 \%$ of benign masses when a pseudocapsule" has not been included in the classification scheme, was a sonographic feature with significant $P$ value (less than 0.05 ) for benignity and thus with a strong predicting power in this material.

Echotexture, commonly divided into homogeneous and heterogeneous echo pattern, was considered as a specific sonographic feature. Homogeneous echotexture was found in $94.4 \%$ of benign masses and in $5.6 \%$ of malignant breast masses \& heterogeneous echotexture was found in $82.1 \%$ of malignant masses and $17.9 \%$ of benign masses (figure .4). Echo texture had a statistically significant ( $\mathrm{P}$ value less than $0.05)$ contribution to the differentiation between benign and malignant tumors. But echogenicity has often been of less importance for the differentiation of solid masses, partly because no standardized definition of this parameter exists. By far most tumors are hypoechoic when compared with the adjacent echogenic fibro-glandular tissue. In this study, $76.2 \%$ of benign masses and $23.8 \%$ of the malignant masses were hypoechoic \& $75 \%$ of the benign \& $25 \%$ malignant masses were hyperechoic (figure .3). More useful information can be gained by comparing tumor echogenicity with that of the fatty tissue of the breast rather than with that of adjacent echogenic fibro-glandular tissue surrounding the tumor nidus [2]. Extensive hypo-echogenicity is a prominent feature of carcinomas. Density perception by the human eye has been considered unreliable in evaluating echogenicity of breast masses, and the difference between density values of malignant and benign masses was also found to be insignificant statistically $(\mathrm{P}$ value $=0.9)$ in this study.

Sound through-transmission is a sonographic feature frequently discussed in the literature. Central posterior shadowing a feature suggesting malignancy was reported in $75 \%$ of malignant masses \& $25 \%$ of benign masses. A bright posterior acoustic enhancement zone corresponding to the posterior margin of the tumor may be suggestive of benignity $(63 \%)$ rather than a malignancy (7\%) (Table .3). The posterior echo-intensity was found to be significant statistically ( $\mathrm{P}$ value less than 0.05 ) in differentiating between benign \& malignant masses.

Ductal extension is a sonographic feature, which has been seen associated less frequently but significant statistically ( $P$ value less than 0.05 ) with malignant breast masses ( 5 cases in this study were malignant) (Table .4). Some features were not significant statistically (with $\mathrm{P}$ value $=0.07$ ) in differentiating between benign \& malignant lesions. For example, the detection of punctuated calcifications on the mass were not a useful determinant of malignant masses, $6(43 \%)$ of them showed punctuated calcifications and of the benign masses, 8 (57\%) showed punctuated calcifications.

We recognized some limitations of our study. These include the fact that the evaluation of the cases was retrospective, which did not reflect actual everyday practice. That the sample size was relatively small and that there was unavoidable case-selection bias.

\section{Conclusion}

Breast ultrasound not only helps in differentiating cystic from solid lesions, but also plays an important role in characterizing solid nodules.

The sonographic features suggestive of malignancy include irregular shaped, ill-defined angular margin, speculations, mcirolobulations, with dimensions of deeper than wider ,posterior acoustic shadowing ,had ductal extension and showed heterogeneous echotexture.

The sonographic features suggestive of benignity include oval\round shaped, well circumscribed margin, macrolobulations, with dimensions of wider than deeper, posterior acoustic enhancement, thin echogenic pseudocapsule and showed homogenous echotexture.

The ability to characterize lesions on breast ultrasound helps to determine the next step in patient care.

Sonography can be used to accurately classify some solid lesions as benign, allowing imaging follow-up rather than biopsy.

\section{References}

[1] Poplack SP, Carney PA, Weiss JE, Titus-Ernstoff L, Goodrich ME, Tosteson AN. Screening mammography:

\section{Volume 4 Issue 12, December 2015}




\section{International Journal of Science and Research (IJSR) \\ ISSN (Online): 2319-7064}

Index Copernicus Value (2013): 6.14 | Impact Factor (2014): 5.611

costs and use of screening-related services. Radiology $2005 ; 234: 79-85$.

[2] Stavros AT, Thickman D, Rapp CL, Dennis MA, Parker SH, Sisney GA. Solid breast nodules: use of sonography to distinguish between benign and malignant lesions. Radiology 1995; 196:123-134.

[3] Bruening W, Launders J, Pinkney N, Kostinsky H, Schoelles K, Turkelson C. Effectiveness of noninvasive diagnostic tests for breast abnormalities: comparative effectiveness review no. 2 (prepared by ECRI Evidencebased Practice Center under contract no. 290-02-0019). Rockville, MD: Agency for Healthcare Research and Quality, 2006.

[4] Alexandra Athanasiou, Anne Tardivon, Lilliane Ollivier, Fabienne Thibault, Carl El Khoury, Sylvia Neuenschwander: How to optimize breast ultrasound: European Journal of Radiology,Volume 69, Issue 1, January 2009, Pages 6-13,Breast Imaging.

[5] Harold Ellis: Clinical Anatomy: Applied Anatomy for Students and Junior Doctors, 11th edition: Anatomy of the breast; 114-115.

[6] Richard E. Fine, MD,Edgar D. Staren, MD, PhD: Surgical Clinics Of North America: Updates in breast ultrasound, Surg Clin N Am 84 (2004) 1001-1034.

[7] Tejas S. Mehta, MD, MPH: Surgical Clinics of North America: Current uses of ultrasound in the evaluation of the breast, Radiol Clin N Am 41 (2003) 841-856.

[8] Walker HK, Hall WD, Hurst JW: Clinical Methods: The History, Physical, and Laboratory Examinations. 3rd edition: Chapter 176, Breast Examination, 1990.

[9] Sandra L.Hagen-Ansert, M.S., RDMS,RDCS.Textbook of Diagnostic Ultrasonography $5^{\text {th }}$ ed.2001: In: M. Elizabeth Glenn. The breast .p.363-394.

[10] Darrell N. Smith, MD. BREAST ULTRASOUND. Radiologic clinics of North America. May 2001, volume 39, NUMBER 3, p.485-497.

[11] Anat Kornecki, MD, FRCPC. Current Status of Breast Ultrasound. Canadian Association of Radiologists Journal. (2011) Volume 62. p. 31-40.

[12] Melania Costantini, MD, Paolo Belli, MD, Roberta Lombardi, MD, Gianluca Franceschini, MD, Antonino Mulè, MD, Lorenzo Bonomo, MD. Characterization of Solid Breast Masses.Use of the Sonographic Breast Imaging Reporting and Data System Lexicon. Journal American Institute of Ultrasound in Medicine. (2006) Volume 25.p.649-659.

[13] Tejas S. Mehta, MD, MPH. Current uses of ultrasound in the evaluation of the breast. Radiologic clinics of North America. 2003, volume 41, p. 841- 856.

[14]N. Mascara, C. Ferranti. Benign breast lesions: Ultrasound. Journal of Ultrasound. (2011), volume 14.p. 55-65.

[15]Fornage BD, Faroux MJ, Simatos A. Breast masses:bUS-guided fine-needle aspiration biopsy.Radiology1987;162:409- 14.

[16] Parker SH, Jobe WE, Dennis MA, Stavros TA, Johnson KK, Yakes WF, et al. US-guided automated largecore breast biopsy. Radiology 1993; 187:507-11.

[17] Parker SH, Burbank F, Jackman RJ, Aucreman CJ, Cardenosa G, Cink TM, et al. Percutaneous large-core breast biopsy: a multi-institutional study. Radiology1994; 193:359- 64.
[18] Harlow SP, Krag DN, Ames SE, Weaver DL. Intraoperative ultrasound localization to guide surgical excision of nonpalpable breast carcinoma. J Am Coll Surg 1999; 189:241-6.

[19] Moore MM, Whitney LA, Cerilli L, Imbrie JZ, Bunch $\mathrm{M}$, Simpson VB, et al. Intraoperative ultrasound is associated with clear lumpectomy margins for palpable infiltrating ductal breast cancer. Ann Surg 2001; 233:761-8.

[20] Smith LF, Rubio IT, Henry-Tillman R, Korourian S, Klimberg VS. Intraoperative ultrasound-guided breast biopsy. Am J Surg 2000; 180:419-23.

[21] DeBruhl ND, Gorczyca DP, Ahn CY, et al: Silicone breast implants: US evaluation. Radiology 1993.189:9598.

[22] Kolb TM, Lichy J, Newhouse JH. Occult cancer in women with dense breasts: detection with screening US-diagnostic yield and tumor characteristics. Radiology 1998; 207:191-199

\section{Author Profile}

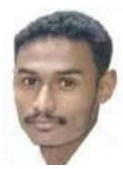

Abdoelrahman Hassan Ali Bakry (Sudan) received the B.Sc. in radiotherapy technology from College of Medical radiological Science, Sudan University of Science and Technology in 2013. During 2013 up to date, he is staying in College of Medical radiological Science, Sudan University of Science and Technology, Radiology Department, Antalya Medical Center and Elnileen Diagnostic Medical Center; also he has been active in Computerized Texture Analysis, Radiotherapy-Oncology, and diagnostic radiology and Nuclear Medicine researches. Now he is assistant teacher at SUST also (2014). 